\title{
PNEUMONIA GRANULOMATOSA POR Aspergillus sp. EM UM CÃO - RELATO DE CASO
}

\author{
(Granulomatous pneumonia by Aspergillus spp. in a dog - case report)
}

\author{
Vinicius Dahm, Juliana Das Chagas Goulart, Arthur Colombari Cheng, Karim Cristhine Pase Montagnini, Carolina Fontana, \\ Amália Ferronato, Estela Dall'Agnol Gianezini, Aline de Marco Viott \\ Universidade Federal do Paraná, Palotina, Paraná, Brasil.
}

*Correspondência: alinedemarco@yahoo.com.br

RESUMO: Dentre as patologias do sistema respiratório dos animais domésticos, as pneumonias micóticas são comuns em certas regiões e normalmente são causadas por fungos que podem ser classificados como fungos de micoses sistêmicas e oportunistas. Os fungos causadores de micoses sistêmicas são primários dos animais e não necessitam de imunossupressão prévia para causar a doença, enquanto os oportunistas não são patógenos primários, porém causam lesões principalmente em indivíduos com um sistema imune incompetente e em pacientes que tenham usado terapia antimicrobiana por períodos prolongados. Destes, o gênero Aspergillus é bem relatado, com destaque ao Aspergillus fumigatus. Apesar de poder acometer tanto animais quanto humanos imunocomprometidos, não se tem relatos de transmissão direta entres as espécies. Geralmente, a lesão encontrada é de pneumonia granulomatosa ou piogranulomatosa (LÓPEZ, 2013). Diante disso, relata-se um caso de pneumonia micótica por Aspergillus sp. diagnosticada pelo Laboratório de Patologia Veterinária (LPV) da Universidade Federal do Paraná - Setor Palotina. Um cão, Labrador macho, deu entrada no LPV, com histórico de tratamento para otite média e interna crônica e apresentando manifestações clínicas neurológicas (tetraplegia, head tilt, torção de pescoço e vocalização). Segundo prontuário clínico o paciente havia sido submetido a um intenso tratamento com antibióticos sistêmicos para tratamento da otite. Em decorrência da piora do quadro clínico neurológico, optou-se pela eutanásia e o animal foi remetido ao LPV, para a autópsia. Na macroscopia, o pulmão apresentava-se congesto, com bordos enfisematosos; as demais áreas pulmonares, encontravam-se hipocrepitantes e ao corte, observou-se discreto edema. Os brônquios apresentavam-se dilatados e com presença de material amorfo brancacento (bronquiectasia) (broncopneumonia). Na microscopia, havia presença de infiltrado inflamatório moderado multifocal de neutrófilos e histiocitos, com moderados macrófagos epitelioides (pneumonia). Notou-se área focalmente extensa contendo material flocular eosinofílico e neutrófilos degenerados, envolvida por discreta quantidade de fibroblastos (abscesso) e, dentro deste, observou-se intensa quantidade de estruturas fúngicas filamentosas, compatíveis com Aspergillus sp. (coloração de Ácido Periódico de Schiff positiva). Esta infecção pode ser decorrente de uso prolongado de antibióticos que permitem o desenvolvimento de fungos oportunistas, desenvolvendo o quadro de pneumonia fúngica. Os achados macroscópicos e microscópicos são compatíveis com pneumonia granulomatosa de origem fúngica, observada pela presença de hifas intralesionais, característica de infecções por Aspergillus spp. Portanto, ressalta-se a importância do exame necroscópico, assim como a utilização de colorações especiais, para um diagnóstico mais preciso.

Palavras-chave: fungos oportunistas; imunocomprometidos; pneumonia micótica

Referência: LÓPEZ, A. Sistema Respiratório, Mediastino e Pleuras. In: ZACHARY, J. F.; MCGAVIN, M. D. Bases da Patologia em Veterinária. 5 ed. Rio de Janeiro: Elsevier, 2013. p. 461-541. 